\title{
VARIATION IN GAS CHROMATOGRAPHY (GC) ANALYSIS IN SETTING UP LABORATORY PROTOCOLS FOR WASTE TO ENERGY NOVEL FIXED BED REACTOR SETUPS
}

\author{
A. T. AL-DHAFEERI ${ }^{1}$, S. M. AL-SALEM ${ }^{2}$, M. H. AL-WADI ${ }^{2}$, H. H. SULTAN ${ }^{2} \&$ H. K. KARAM ${ }^{2}$ \\ ${ }^{1}$ Water Research Centre (WRC), Kuwait Institute for Scientific Research (KISR), Kuwait. \\ ${ }^{2}$ Environment \& Life Sciences Research Centre (ELSRC), \\ Kuwait Institute for Scientific Research (KISR), Kuwait.
}

\begin{abstract}
Gas Chromatography coupled with Mass Spectrometry (GC/MS) has been applied in various analytical chemistry works. However, to fine tune a system that can serve the purposes of pyrolysis oil identification has proven to be a laborious effort, especially when considering the fact that no standard protocol exists for such analysis. In addition, obtained products were yielded from a newly commissioned unit with a unique and novel design. In this study, a US patent office claimed reactor [SULTAN-1, Pyrolysis Reactor System for the Conversion and Analysis of Organic Solid Waste, Patent application number: $15,487,351]$ that degrades polyolefinc virgin and waste materials to obtain petroleum refinery and petrochemical feedstock, has been commissioned. The reactor produces three distinct physical states of matter products accumulated as testing specimens, i.e. solids, gaseous and oil. The samples analysed in this work were of the gas and oil produced by pyrolysis of end of life tyre (ELTs) shavings that required to have a special recipe to work with in the laboratory. Various MS cords were utilised and experimental setups to fine tune the process, and special emphasis was given on the gas samples variation in this communication. To reach the desired analysis results with high repeatability, a plethora of experiences of lab personnel and laboratory-based experimental work was accumulated. Laboratory protocols were also setup for this work. These will be detailed along the process execution which yielded a standard laboratory best practice analytical method as part of the State of Kuwait newly initiated Government Initiative project.

Keywords: analytical method, GC/MS, laboratory best practice, pyrolysis, rubber, tyres.
\end{abstract}

\section{INTRODUCTION}

\subsection{ELTs in The Context of Solid Waste Management (SWM)}

Solid waste (SW) comes from various sources. It is essential to understand the characteristics of the SW in question, in order to, be able to mange it in an optimal manner. Rubber and durable goods are typically considered as a debatable item, in terms of SW classification [1]. Namely, ELTs where globally some 1.5 billion tyres are produced annually and are presumed to be disposed of within the SW stream [2]. About $80 \%$ of new tyre sales are presumed to be discarded as ELTs in the 15 European Union (EU) member states, equivalent to a disposal rate of 2.5 million tonnes per annum [3].

In many countries, ELTs are not considered to be a municipal solid waste (MSW) per se but are rather categorised as 'special waste' or 'durable products'. In 2010, about 3.3 million tonnes of ELTs were generated in the EU-27 member states and some 5.7 million ELTs were stockpiled throughout Europe [4]. ELTs accumulation in stockpiles is also considered as a serious fire hazard threat causing a near impossible situation to control which may produce large quantities of toxic compounds. Recently, such incidents occurred in Spain and Germany within Europe. 


\subsection{Origins and Chemical Recycling of ELTs}

ELTs contain a high fraction of polymeric materials originating from petrochemical feedstock processed from petroleum-refining operations. These chemicals are high their calorific value $(\mathrm{CV})$ and represent a good venture for recovery as a feedstock recycling process $[5,6]$. The major chemical compounds typically found in ELTs are polyisoprene (PI), polybutadiene (PBD) and a significant proportion of styrene-butadiene-rubber (SBR) [3,7]. It should be kept in mind that both natural and synthetic rubbers are also main constituents of ELTs. This makes ELTs rich in synthetic polymers to be valorised for many industrial processes with the aim of SW recycling.

Pyrolysis is the thermal degradation of organic materials in the presence of heat surrounded by an inert atmosphere. Pyrolysis of ELTs is typically conducted at temperatures above $500^{\circ} \mathrm{C}$ in an open vent or atmospheric pressure. Pyrolysis yields three distinctive products, i.e. pyrolysis oil, gaseous fraction and solid char [8]. The recovery of steel from ELTs can be conducted either pre or post the process itself [1]. The oil resulting from the process can be used directly as a fuel similar to fuel oil or gas oil. It can also be added to refinery product cuts or upgraded using a catalyst [9]. Various studies were conducted in the past on ELTs utilising pyrolysis and where deemed successful [10-15].

\subsection{GC Analytical Methods of ELTs Products Identification}

Analytical methods are typically used post treatment, or coupled with the instrument to conduct the pyrolytic reaction. To compare the analysis of the products between the pyrolysis and combustion of ELTs, Conesa et al. [16] used an experimental setup treating the feedstock and analysing the products with standard chemicals. Poly aromatics and other compounds were analysed using high resolution GC coupled to a high resolution mass spectrometer (MS) (HRGC/HRMS). Volatile organic compounds evolving from the various apparatus were analysed using GC and namely three different columns in Conesa et al. [17] work as per the following: Alumina- $\mathrm{KCl}$ with a flame ionisation detector (FID) for light hydrocarbons $\left(\mathrm{CH}_{4}\right.$, $\mathrm{C}_{2} \mathrm{H}_{6}, \mathrm{C}_{2} \mathrm{H}_{4}+\mathrm{C}_{2} \mathrm{H}_{2}, \mathrm{C}_{3} \mathrm{H}_{6}, \mathrm{C}_{4}$ and $\mathrm{C}_{5}$ hydrocarbons), a Carbosieve SII column with a TCD for $\mathrm{CO}_{2}$ analysis, and a Molecular Sieve 5 Plot column to separate nitrogen, oxygen, and $\mathrm{CO}$.

Chang [18] utilised GC with dual TCD/FID to analyse the composition of oil produced from pyrolysis. Hence, variation exists in open literature regarding the use of appropriate equipment for product analysis. This is expected, since products have different compositions and both qualitative and quantitative analyses were conducted in the past. Therefore, to have a standard recipe or procedure for products analysis from pyrolysis is something that needs to be done for each equipment (or apparatus) depending on targeted compounds and what is expected to be gained from the analysis (and consequently the study).

\subsection{Work Motivation}

ELTs accumulation in stockpiles has been deemed as a serious environmental hazard. Moreover, it was announced in the near past that the State of Kuwait was the home of the largest ELTs disposal site, visible from space. The area of Sulaibyia (Ruhayia) (see Fig. 1) hosts over 7 million tyres in one place [19]. There were also a number of reported incidents where ELTs caught fire. The Government of Kuwait is now taking an initiative to dispose and control the situation utilising technological means that can maximise the use of this SW. 


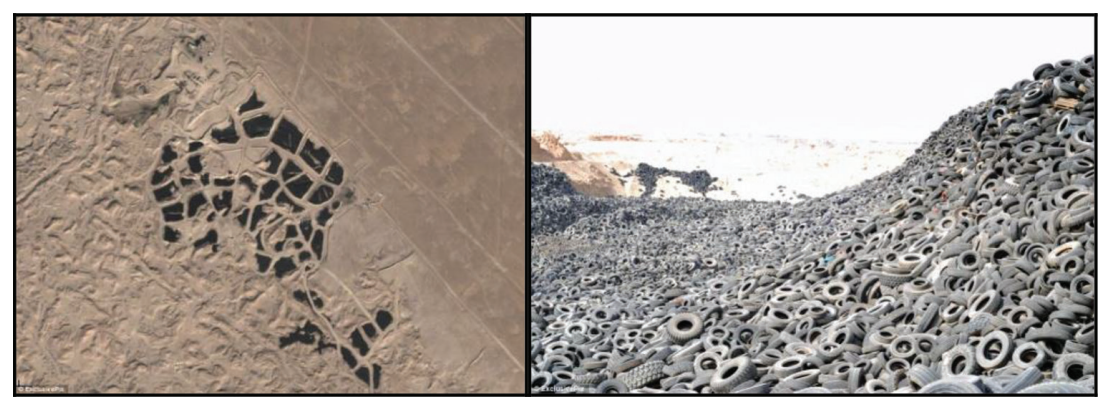

Figure 1: Aerial (left) and top (right) view of the ELTs stockpile location in the State of Kuwait. Images source [19].

To this end, and given the rationale and reasons stated above; this work was initiated of dire necessity to the current situation in Kuwait when it comes to the management of ELTs. This study investigates a number of technical objectives and research statements and its specific objectives are as per the following:

i. To utilise a novel bench scale reactor that conducts batch process pyrolysis on a local ELTs grade.

ii. To determine major compounds obtained from the pyrolysis of local ELTs grade.

iii. To study the variation from conducting various methods of analytical analysis on products obtained.

iv. To develop and consequently come up with final recommendation, as to the best practice in handling ELTs pyrolysis and protocols that govern its execution.

The work presented in this study stems from an ongoing effort in executing a national government initiative project in establishing a waste management research unit (WMRU). The preliminary analysis conducted in this study is being accumulated with ongoing research efforts to establish the above-mentioned objectives and fine tune resulting efforts in the WMRU of the Kuwait Institute for Scientific Research (KISR).

\section{EXPERIMENTAL}

\subsection{Materials}

A locally sourced tyre grade deemed as scrap was secured from a local dealer in Kuwait in the amount of $10 \mathrm{~kg}$. The ELTs were used in the form of shavings as received (Fig. 2). The average dimensions of the ELTs were $30 \times 30 \mathrm{~mm}$. Sample size was also verified using a JEOL-JSM-6010 LA SEM using a voltage of $3 \mathrm{kV}$ resulting in various micrographs (Fig. 3).

\subsection{Pyrolysis Bench Scale System}

A total of $200 \mathrm{~g}$ of ELTs were charged into the fixed bed batch reactor system. The reactor system and configuration is of a novel design and recently patented (SULTAN 1-Pyrolysis Reactor System for the Conversion and Analysis of Organic Solid Waste, Patent application 


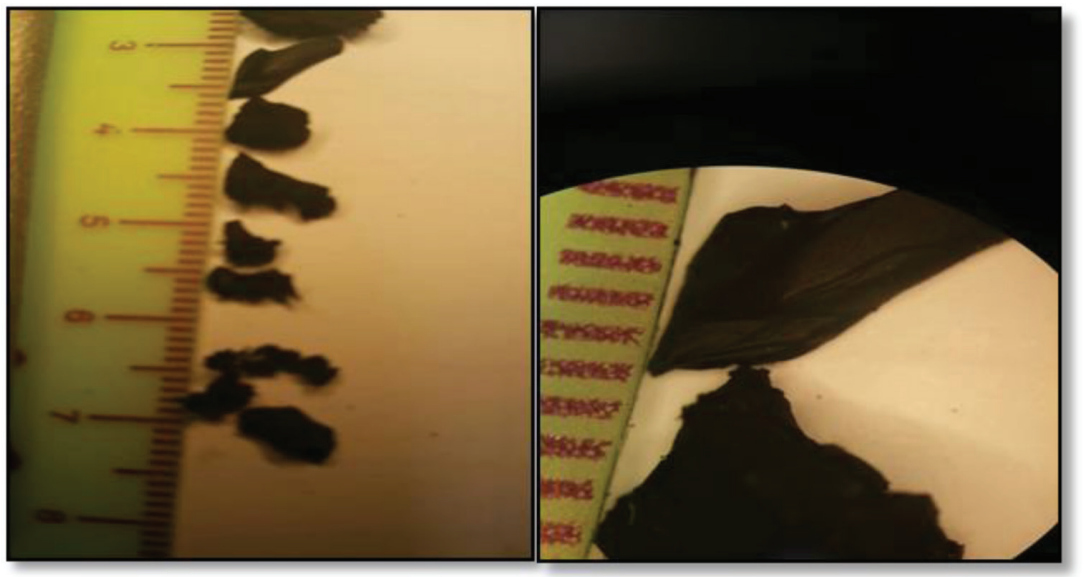

Figure 2: End of life tyres (ELTs) shavings used in this study.

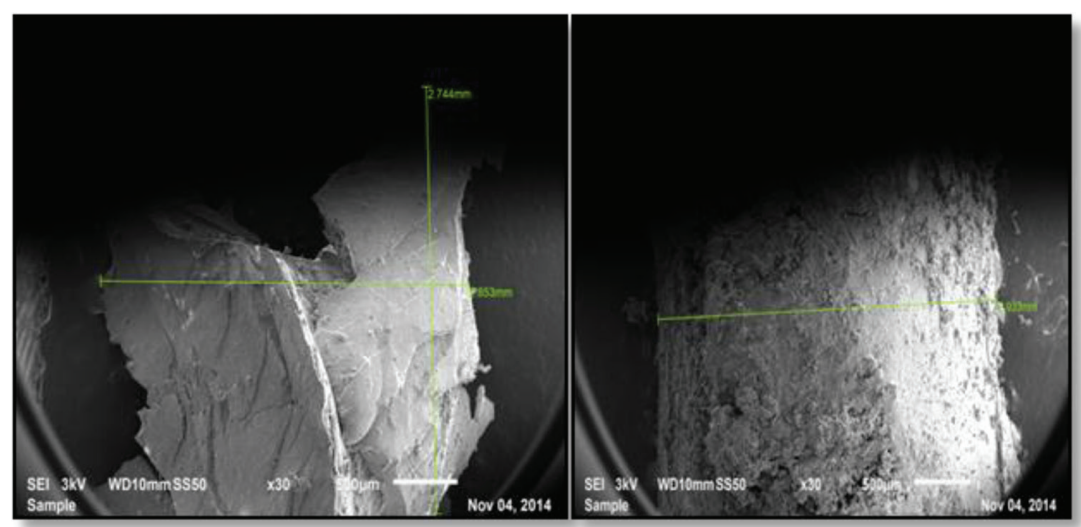

Figure 3: Scanning electron microscopy (SEM) images obtained for particle size dimension of ELTs.

number: 15,487,351). A minimum of two duplicate runs were conducted on the ELTs in the range between $500^{\circ} \mathrm{C}$ to $700^{\circ} \mathrm{C}$ (Figs. $4 \& 5$ ). Alumina packing of a 5-mm diameter (average bulk density- $\rho-700 \mathrm{~kg} \mathrm{~m}^{-3}$ ) was used in the amount of $120 \mathrm{~g}$. A cooling temperature of $20^{\circ} \mathrm{C}$ was used for the chilling unit. Gases evolved were collected in a Tedllar bag (5 L) over the course of the conducted run.

\subsection{GC Analysis Laboratory Protocol}

Two methods were used to establish the GC/MS protocol in this work for the gaseous and oil fraction obtained from the pyrolysis process. In the laboratory procedure, the gas and oil samples were received from the experiments that required a different analytical approach. Gas samples did not required any sample preparation step and were analysed as is. On the other hand, oil samples were not suitable for a direct injection and as a consequence a cleanup step was included in the analytical procedure. The GC-MS analysis was performed in an 


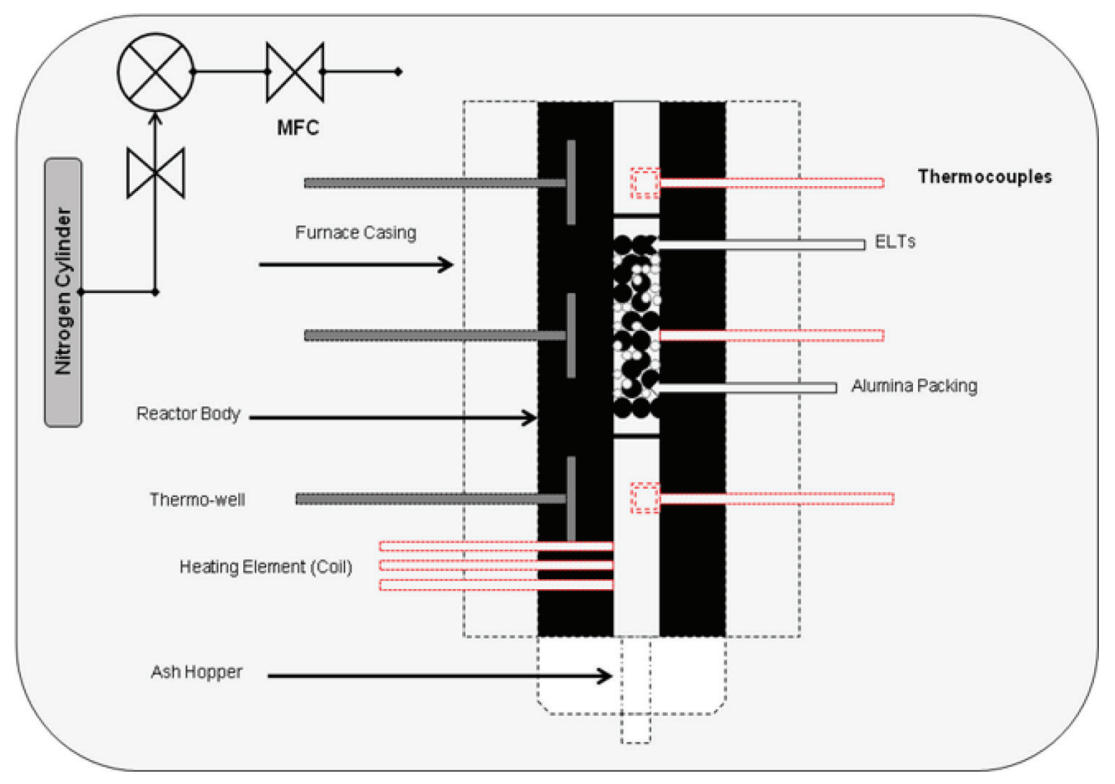

Figure 4: Schematic Flow Diagram of the Reactor Configuration

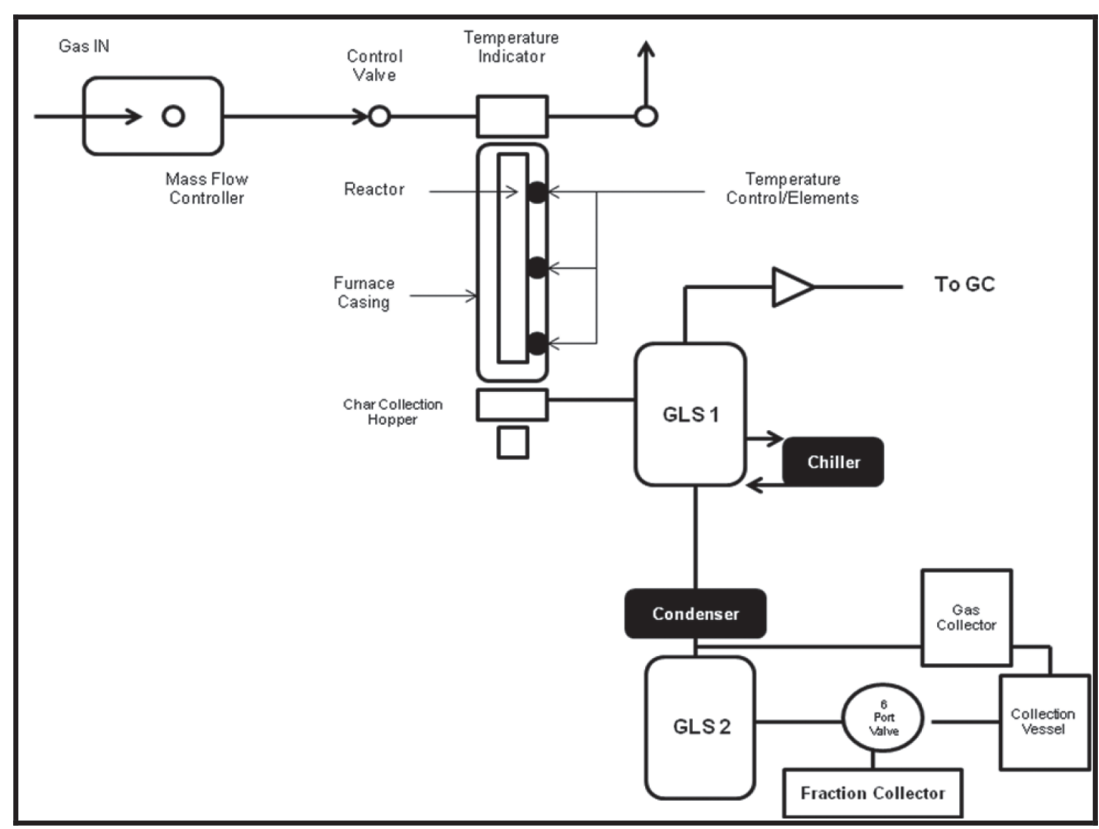

Figure 5: Pyrolytic system configuration and setup used in the waste management research unit (WMRU). 
Agilent 5977A GC/MSD system. The initial tests were carried out in a 15-m column (Restek-5MS $15 \mathrm{~m}, 0.25 \mathrm{~mm}, 0.25 \mu \mathrm{m}$ ). A $30-\mathrm{m}$ column was also installed (Restek-5MS $30 \mathrm{~m}, 0.25 \mathrm{~mm}, 0.25 \mu \mathrm{m})$ and experimented with. Mass detector was operated in EI and Scan mode $(50-550 \mathrm{~m} / \mathrm{z})$. The qualitative analysis was performed with MassHunter using a deconvolution algorithm to find the compounds in the chromatogram and the identification of the potential compounds were carried out comparing their spectra with the ones included in the NIST 2014 Library. Adsorption chromatography was used to clean-up the oil samples. A glass column containing $5 \mathrm{~g}$ silica and $5 \mathrm{~g}$ alumina was prepared and conditioned with hexane. An amount of $2 \mathrm{ml}$ of the sample was introduced on the top of the column and allowed to pass through it. The elution was carried out with $100 \mathrm{ml}$ of hexane. Gas samples were manually injected $(10 \mu \mathrm{l})$ in splitless mode. That is why the system was reconfigured by removing the auto-sampler and the sample tray. In contrast, oil samples were injected $(1 \mu \mathrm{l})$ in split mode (ratio: 300:1) using the auto-sampler.

Procedures for the detection and identification of compounds in pyrolysis oils for the second set of experiments, are described based on two different clean-up approaches prior to injections of samples. The first procedure was the solid phase extraction (SPE), which is one of the most popular sample preparation techniques used as an alternative to liquid-liquid extraction (LLE). SPE is an extremely versatile technique for the extraction of a wide range of compounds. SPE is performed in cartridges packed with various packing materials ranging from polar to non-polar ones; typically similar phases as used in liquid chromatography. The stationary phase is conditioned prior to loading of the sample. Conditioning is performed using different solvents to remove any impurities and to 'wet' the stationary phase.

After conditioning the silica cartridge $(1.0 \mathrm{~g} / 6 \mathrm{ml})$ with hexane the sample $(0.2 \mathrm{ml}$ in $1 \mathrm{ml}$ hexane) was loaded and the cartridge was rinsed with a weak eluent to remove sample impurities which are not of interest. Subsequently, the analytes of interest are eluted by a 6-ml dichloromethane with a polarity similar to target compounds. Solvent was evaporated under nitrogen for GC/MS injection. In order to improve the flow of the sample and solvents, vacuum was used. The choice of the stationary phase depends on the nature of the analytes. The second procedure to be experimented with was the back extraction of semi-polar and polar organic volatile compound, which was performed by mixing $5 \mathrm{ml}$ of deionised water with $2 \mathrm{ml}$ of TDO. The mixture was shaken vigorously and then centrifuged for $10 \mathrm{~min}$ at 3,000 rpm to allow separation of the aqueous and organic layer. The aqueous layer was removed and back extracted with DCM using $4 \mathrm{ml}$ aqueous layer and $2 \mathrm{ml}$ of DCM. The DCM was removed and dried on anhydrous $\mathrm{Na}_{2} \mathrm{SO}_{4}$. The extract was injected by auto-sampler for GC/MS analysis.

\section{RESULTS AND DISCUSSION}

The results of the GC analysis will be detailed in this section, with respect to each analytical method used. The first set of gas samples were analysed in a 15-m column. Unfortunately, those samples were not reanalysed in the $30-\mathrm{m}$ columns because only five sampling bags were available and they were required for new sampling episodes. To avoid cross-contamination among samples, the sampling bags were cleaned and purged with nitrogen gas. This gives one of the main indicators in running this experiments laboratory protocols where sufficient personnel in needed for the change in shift within the GC lab. A sample of the results from gas samples is shown in Table 1 and a sample of the absolute abundance (peak area) of the compound detected is shown in Figure 6. Silicone Contaminants, aliphatic compounds (long-chain alkane hydrocarbon) and sulphur compounds were detected in all of them. A combination of low temperature in the pyrolysis experiment and a 15-m column could justify 
Table 1: Gas chromatography results using 15-m column on the gas product from ELTs at $500^{\circ} \mathrm{C}$ (operating temperature).

\begin{tabular}{|c|c|c|c|}
\hline $\begin{array}{l}\text { Compound detected in exp. } \\
\text { run } \# 1\end{array}$ & $\begin{array}{l}\text { Amount } \\
(\%)\end{array}$ & $\begin{array}{l}\text { Compound detected in exp. } \\
\text { run } \# 2\end{array}$ & $\begin{array}{l}\text { Amount } \\
(\%)\end{array}$ \\
\hline Sulfur (S8) & 40 & Sulfur (S8) & 33 \\
\hline Homosalate & 16 & $\begin{array}{l}\text { Phenol, 2,2'-methylenebis[6- } \\
\text { (1,1-dimethylethyl)-4-ethyl- }\end{array}$ & 29 \\
\hline Hexathiane & 16 & Hexathiane & 29 \\
\hline Hexadecanoic acid, methyl ester & 11 & D-Limonene & 6 \\
\hline $\begin{array}{l}\text { Cyclopentasiloxane, } \\
\text { decamethyl- }\end{array}$ & 11 & $\begin{array}{l}\text { Cyclohexasiloxane, } \\
\text { dodecamethyl- }\end{array}$ & 2 \\
\hline $\begin{array}{l}\text { Cyclooctasiloxane, } \\
\text { hexadecamethyl- }\end{array}$ & 2 & $\begin{array}{l}\text { Cycloheptasiloxane, } \\
\text { tetradecamethyl- }\end{array}$ & 1 \\
\hline $\begin{array}{l}\text { Cyclohexasiloxane, } \\
\text { dodecamethyl- }\end{array}$ & 1 & $\begin{array}{l}\text { 3H-1,2-Dithiole-3-thione, } \\
\text { 4-methyl- }\end{array}$ & 1 \\
\hline $\begin{array}{l}\text { Cycloheptasiloxane, } \\
\text { tetradecamethyl- }\end{array}$ & 1 & & \\
\hline $\begin{array}{l}\text { 2-Ethylhexyl trans-4- } \\
\text { methoxycinnamate }\end{array}$ & 1 & & \\
\hline $\begin{array}{l}\text { 13-Octadecenoic acid, methyl } \\
\text { ester }\end{array}$ & 0.2 & & \\
\hline
\end{tabular}

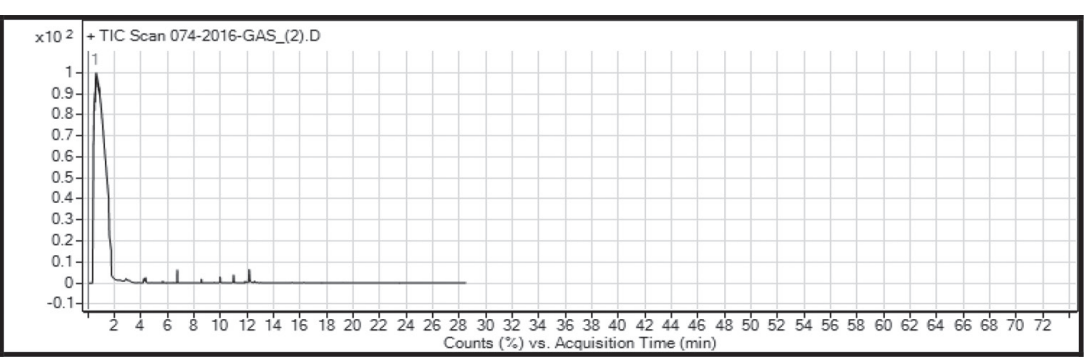

Figure 6: GC scan of Run no. $1\left(500^{\circ} \mathrm{C}\right)$ gas product showing count (\%) vs. acquisition time (min) on the 15-m column.

the fact that in the first set of samples the number of compounds detected were lower than in the second set of gas samples on the 30- m column. Detection for larger amount of compounds was conducted later on at retention times below 5 min. By comparison to $30-\mathrm{m}$ column, detection was higher for the $700^{\circ} \mathrm{C}$ gas product (Fig. 7).

The complexity of the oil sample chromatograms were higher as expected. The number of compounds that could be identified were also higher than in gas product samples. A considerable number of aromatic compounds appeared in the chromatogram such as benzene derivatives, polycyclic aromatic hydrocarbons (PAHs) hydro and methyl derivatives. The Total Ion Chromatogram (TIC) were also analysed for the samples. Internal standards are 


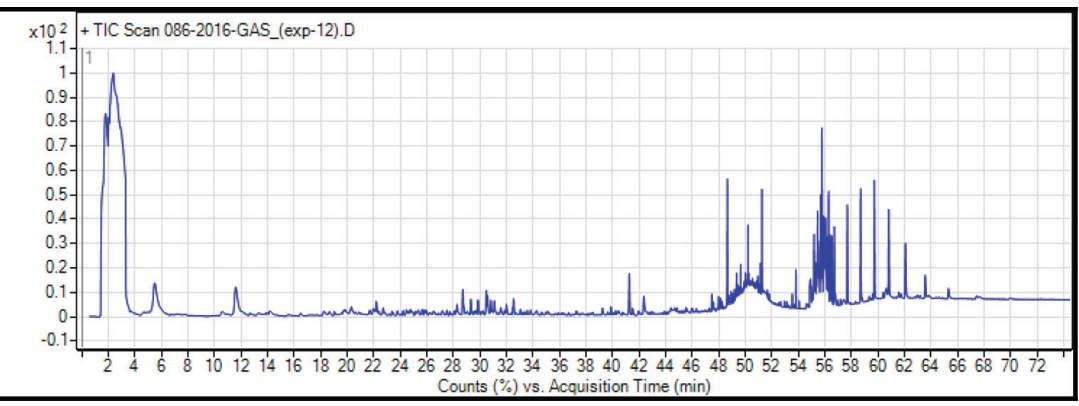

Figure 7: GC scan of Run no. $2\left(700^{\circ} \mathrm{C}\right)$ gas product showing count (\%) vs. acquisition time (min) on the 30-m column.

advised to be added to the oil extracts before injection to have a more accurate semi-quantitative analysis. Space limitation in this correspondence has limited showing all results obtained (gas and liquid). However, Figure 8 shows samples of the derived results from the oil analysed. Al-Salem et al. [5] pyrolysed $15 \mathrm{mg}$ of tyre scrap in a micro setup (thermogravimetry) and analysed the products using the means of a chromatograph provided with a thermal conductivity (TCD) and FID connected to the micro balance using a thermostated

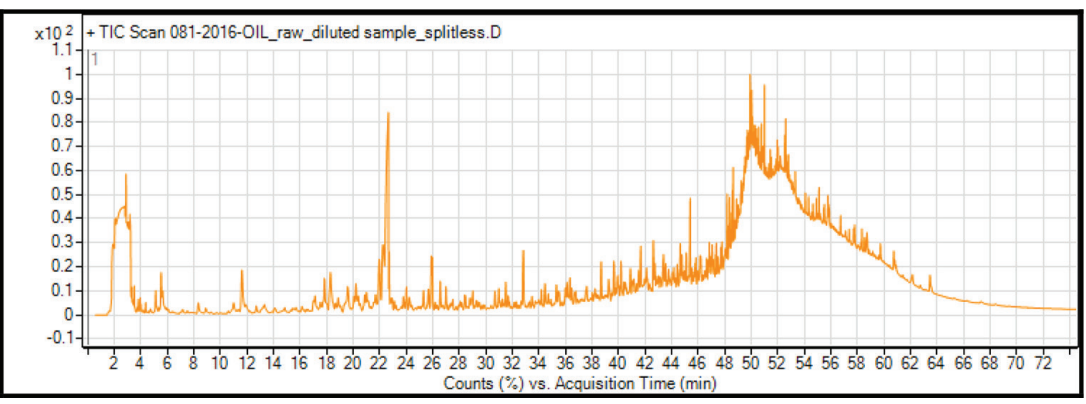

Figure 8: GC scan of Run no. $2\left(550^{\circ} \mathrm{C}\right)$ oil product showing count $(\%)$ vs. acquisition time (min) on the 30-m column.

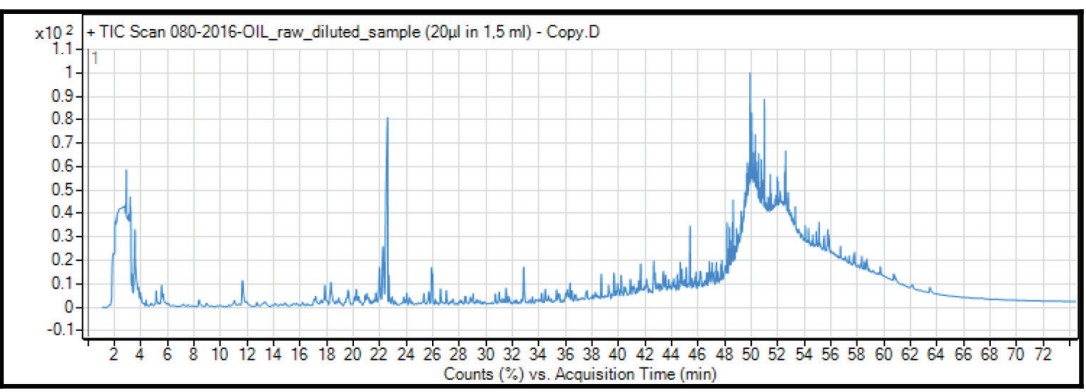

Figure 9: GC scan of Run no. $1\left(550^{\circ} \mathrm{C}\right)$ oil product showing count (\%) vs. acquisition time (min) on the 30-m column. 
line. The identification of the products was conducted in a lump product fashion categorising the evolved compounds from pyrolysis as per the following: gases $\left(\mathrm{C}_{1}-\mathrm{C}_{4}\right)$, liquids (nonaromatic $\left.\mathrm{C}_{5}-\mathrm{C}_{10}\right)$, single ring aromatics $\left(\mathrm{C}_{5}-\mathrm{C}_{10}\right)$, and char.

A more detailed spectra was detected using the second method applied for the GC ELT oil samples, explained in the previous section. This can be attributed to the retention time increase in GC and the SSE (preparation method). Hence, SSE is more appropriate for ELTs and can be highly recommended for future works. The library matching procedure using the Nist 02 (National Institute of Standards and Technology, Gaithersburg, MD, USA) was also conducted. As criterion, a minimum spectral match factor of $70 \%$ was used. The major compounds identified were as follows: Cyclohexane, 2,2,4-Trimethyl Petane, Heptane, 4,4-dimethy cyclopetane, 2,4- dimethyl 1,3 Pentene, 2,4,4-trimethyl 1-Pentadiene, 3,5-Dimethyl cyclopentene, Methyl cyclohexane, 3,4,4 trimethyl 2-Pentene, 3, methyl cyclohexene and Styrene. Other compounds are reported in Table 2 and scans are shown in Figs 10 and 11. It can be noted that more PAHs are detected with the SLE method due to the contact with the pre-treatment cartridge allowing for developing a better separation phase for analysis.

Table 2: Main compounds detected with the SLE method for GC oil analysis.

\begin{tabular}{ll}
\hline Compound & Compound \\
\hline Methyl Iso butyl Ketone & 3,5 dimethyl cyclopetene \\
Toluene & $2,2,4,4$ tetramethyl Pentane \\
3,5-dimethyl cyclohexene & Ethyl benzene \\
P-xylene & $3-1$ methyl cyclohexane \\
O-Xylene & Styrene \\
1,5,5-Trimethyl 6- methylene Cyclohexene & m- Cymene \\
D-Limonene & \\
$1,3,5$-trimethyl benzene & Naphthalene \\
\hline
\end{tabular}

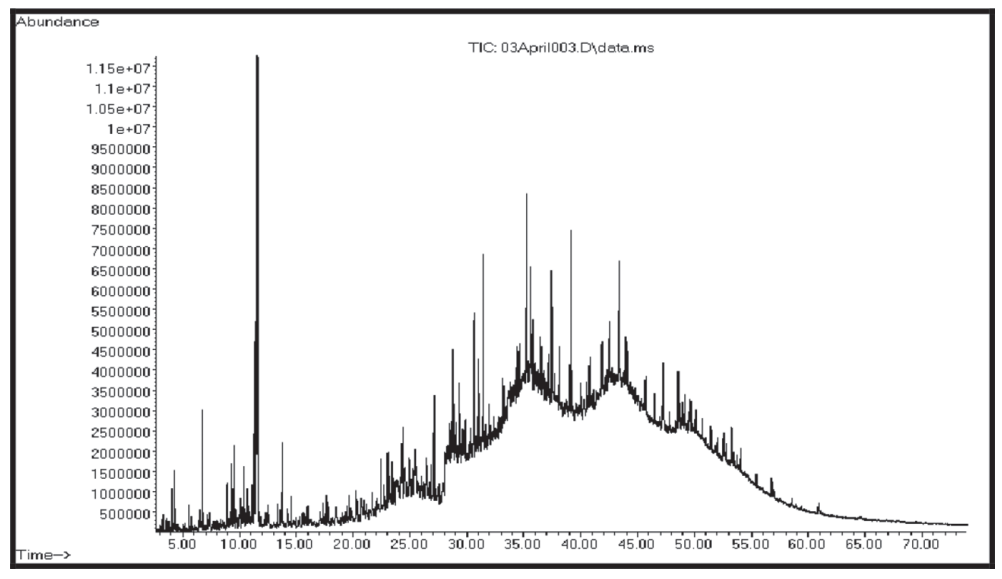

Figure 10: GC scan pyrolysis oil using SLE method. 


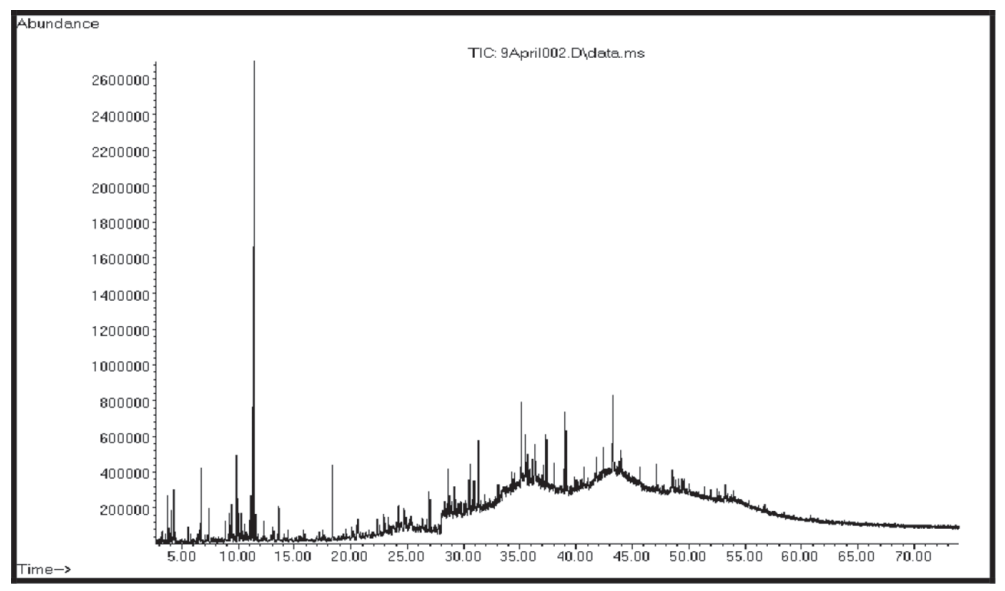

Figure 11: GC scan pyrolysis oil using LLE method.

\section{CONCLUSIONS}

The variation in chord (column) length and the detection time interpretation of the GC results contribute considerably in the analysis of the pyrolysis gas and oil samples. The preliminary work conducted in this study indicates so far that the GC protocol ideal for analysis in these cases is noted as the protocol shown for SPE. For higher detection scan and limit in retention time compounds, results are ideal to be analysed from start of scan rather than after 4 to 6 min of retention time in columns. This was noted for gaseous samples, since past works have not indicated a clear protocol for such analysis.

\section{ACKNOWLEDGMENT}

The authors are grateful to the Kuwait Institute for Scientific Research (KISR) and the Governmental Project Committee (GPC) for their financial support to the work. Kuwait Foundation for the Advancement of Sciences (KFAS) support to this scientific mission is highly appreciated.

\section{REFERENCES}

[1] United States Environmental Protection Agency (EPA). Hazardous waste proposed guidelines and regulations, no. 43 FR 58946, 1978

[2] Williams, P.T., Pyrolysis of waste tyres: a review. Waste Management, 33, pp. 17141728, 2013. https://doi.org/10.1016/j.wasman.2013.05.003

[3] Zabaniotou, A.A. \& Stavropoulos, G., Pyrolysis of used automobile tires and residual char utilization. Journal of Analytical \& Applied Pyrolysis, 70, pp. 711-722, 2003. https://doi.org/10.1016/s0165-2370(03)00042-1

[4] ETRMA, End of life tyres: a valuable resource with growing potential; 2011 Edition, European tyre and rubber manufacturers association, Brussels, Belgium, 2011.

[5] Al-Salem, S.M., Lettieri, P. \& Baeyens, J., Kinetics and product distribution of end of life tyres (ELTs) pyrolysis: a novel approach in polyisoprene and SBR thermal cracking. Journal of Hazardous Materials, 172(2-3), pp. 1690-1694, 2009.

https://doi.org/10.1016/j.jhazmat.2009.07.127 
[6] Al-Salem, S.M., Antelava, A., Constantinou, A., Manos, G. \& Dutta, A., A review on thermal and catalytic pyrolysis of plastic solid waste (PSW). Journal of Environmental Management, 197, pp. 177-198, 2017.

https://doi.org/10.1016/j.jenvman.2017.03.084

[7] Williams, P.T., Besler, S. \& Taylor, D.T., The pyrolysis of scrap automotive tyres: the influence of temperature and heating rate on product composition. Fuel, 69, pp. 1474-1482, 1990.

https://doi.org/10.1016/0016-2361(90)90193-t

[8] Al-Salem, S.M., Lettieri, P. \& Baeyens, J., Recycling and recovery routes of plastic solid waste (PSW): a review. Waste Management, 29(10), pp. 2625-2643, 2009. https://doi.org/10.1016/j.wasman.2009.06.004

[9] Chandrasekaran, S.R., Kunwar, B., Moser, B.R., Rajagopala, N. \& Sharma, B.K., Catalytic thermal cracking of postconsumer waste plastics to fuels. 1. Kinetics and Optimization. Energy Fuels, 29, pp. 6068-6077, 2015. https://doi.org/10.1021/acs.energyfuels.5b01083

[10] Aydin, H. \& Ilk1lıc, C., Optimization of fuel production from waste vehicle tires by pyrolysis and resembling to diesel fuel by various desulfurization methods. Fuel, 102, pp. 605-612, 2012. https://doi.org/10.1016/j.fuel.2012.06.067

[11] Leung, D.Y.C., Yin, X.L., Zhao, Z.L., Xu, B.Y. \& Chen, Y., Pyrolysis of tire powder: Influence of operation variables on the composition and yields of gaseous product. Fuel Processing Technology, 79, pp. 141-155, 2002. https://doi.org/10.1016/s0378-3820(02)00109-1

[12] Al-Salem, S.M., Sharma, B.K., Khan, A.R., Arnold, J.C., Alston, S.M., Chandrasekaran, S.R. \& Al-Dhafeeri, A.T., Thermal degradation kinetics of virgin Polypropylene (PP) and PP with starch blends exposed to natural weathering. Industrial \& Engineering Chemistry Research, 56(18), pp. 5210-5220, 2017. https://doi.org/10.1021/acs.iecr.7b00754

[13] Al-Salem, S.M. \& Lettieri, P., Kinetic study of high density polyethylene (HDPE) pyrolysis. Chemical Engineering Research \& Design, 88(12), pp. 1599-1606, 2010. https://doi.org/10.1016/j.cherd.2010.03.012

[14] Al-Salem, S.M., Lettieri, P. \& Baeyens, J., The valorization of plastic solid waste (PSW) by primary to quaternary routes: From re-use to energy and chemicals. Progress in Energy \& Combustion Science, 36(1), pp. 103-129, 2010.

https://doi.org/10.1016/j.pecs.2009.09.001

[15] Chen, J.H., Chen, K.S. \& Tong, L.Y., On the pyrolysis kinetics of scrap automotive tires. Journal of Hazardous Materials, B84, pp. 43-55, 2001. https://doi.org/10.1016/s0304-3894(01)00180-7

[16] Conesa, J.A., Font, R., Fullana, A., Martın-Gullon, I., Aracil, I., Galvez, A., Molto, J. \& Gomez-Rico, M.F., Comparison between emissions from the pyrolysis and combustion of different wastes. Journal of Analytical and Applied Pyrolysis, 84(1), pp. 95-102, 2009.

https://doi.org/10.1016/j.jaap.2008.11.022

[17] Conesa, J.A., Fullana, A. \& Font, R., Tire pyrolysis: evolution of volatile and semivolatile compounds. Energy \& Fuels, 14(2), pp. 409-418, 2000.

https://doi.org/10.1021/ef990155w 
[18] Chang, Y.M., On pyrolysis of waste tire: degradation rate and product yields. Resources, Conservation and Recycling, 17, pp. 125-139, 1996.

https://doi.org/10.1016/0921-3449(96)01059-2

[19] Daily Mail, World's biggest tyre graveyard: Incredible images of Kuwaiti landfill site that is home to seven million wheels and so huge it can be seen from space, 2003. 